\title{
Mapping the Wind Hazard of Global Tropical Cyclones with Parametric Wind Field Models by Considering the Effects of Local Factors
}

\author{
Chenyan Tan ${ }^{1,2}$ - Weihua Fang ${ }^{1,2}$
}

Published online: 7 February 2018

(C) The Author(s) 2018. This article is an open access publication

\begin{abstract}
Tropical cyclones (TCs) cause catastrophic loss in many coastal areas of the world. TC wind hazard maps can play an important role in disaster management. A good representation of local factors reflecting the effects of spatially heterogeneous terrain and land cover is critical to evaluation of TC wind hazard. Very few studies, however, provide global wind hazard assessment results that consider detailed local effects. In this study, the wind fields of historical TCs were simulated with parametric models in which the planetary boundary layer models explicitly integrate local effects at $1 \mathrm{~km}$ resolution. The topographic effects for eight wind directions were quantified over four types of terrain (ground, escarpment, ridge, and valley), and the surface roughness lengths were estimated from a global land cover map. The missing TC parameters in the best track datasets were reconstructed with local regression models. Finally, an example of a wind hazard map in the form of wind speeds under a 100-year return period and corresponding uncertainties was created based on a statistical analysis of reconstructed historical wind fields over seven of the world's ocean basins.
\end{abstract}

Keywords Surface roughness - Topographic effect · Tropical cyclone · Wind field model · Wind hazard

Weihua Fang

weihua.fang@bnu.edu.cn

1 Key Laboratory of Environmental Change and Natural Disaster of Ministry of Education, Faculty of Geographical Science, Beijing Normal University, Beijing 100875, China

2 Academy of Disaster Reduction and Emergency Management, Ministry of Civil Affairs and Ministry of Education, Beijing Normal University, Beijing 100875, China

\section{Introduction}

Tropical cyclones (TCs) cause casualties and enormous economic losses in the coastal areas of the world (GuhaSapir et al. 2013). Annually, there are approximately 90 TCs globally (Knapp et al. 2010). Wind is one of the major hazards of TCs, which not only brings direct property damage but also determines the intensity of other secondary hazards, such as storm surge and waves.

Tropical cyclonic wind hazard is often quantified by the statistical distribution of storm intensity and frequency and is delineated in the form of a wind speed map of the return period (Fang and Lin 2013). For a single site, the frequency of wind speeds is usually analyzed with methods like the extreme value theory (EVT), which is based on historical ground meteorological observations (Elsner et al. 2008). For local areas, ground observations might be insufficient and modeling of historical or stochastic simulated TCs based on the Monte-Carlo method (Russell 1969; Huang et al. 2001) is needed. For larger areas, methods using basin-wide stochastic simulations of full TC tracks have been developed (Vickery et al. 2000; Emanuel et al. 2006).

A TC wind field can be simulated by numerical or parametric methods. Although numerical models, such as the Weather Research and Forecasting (WRF) model (Skamarock et al. 2005; Nolan et al. 2009), have been widely used in wind field reconstruction and forecasting, parametric wind field models gained popularity in TC wind hazard assessment for their satisfactory modeling accuracy with limited TC parameters as inputs. Usually, the key parameters can be obtained from historical TC track datasets, and great efforts have been made to compile the best tracks around the globe (Knapp et al. 2010). But derived parameter values sometimes are of low reliability, 
and the poor quality of TC parameters may influence the reliability of parametric models.

Progress on TC wind hazard assessment displays great regional disparity among countries and regions. At the country level, wind hazard models have been developed and widely applied in several TC-prone countries. For example, in the United States, the HAZUS hurricane model has been developed and improved since 1997 (FEMA 2012), and the Florida Office of Insurance Regulation has supported the development of the Florida Public Hurricane Loss Model (FIU 2011). In Central America, the Comprehensive Approach to Probabilistic Risk Assessment (CAPRA) has been developed covering many countries (Cardona et al. 2012), and, in Australia, the Tropical Cyclone Risk Model (TCRM) was developed in 2008 (Arthur et al. 2008) and was released in 2011 (Summons and Arthur 2011). At the global scale, the global historical TC wind fields (1970-2010) were simulated in 2011 using a parametric wind field model (Holland model) for all basins around the world, which was supported by UNEP (UNISDR 2009, 2011). Based on this study, global wind speed maps at various return periods were derived (Giuliani and Peduzzi 2011), and the methods were slightly improved in 2013 and 2015 (CIMNE 2013; UNISDR 2013, 2015).

A large gap still exists in the improvement of global wind hazard assessment. In general, wind hazards are spatially heterogeneous, and local factors, such as altitude, slope and aspect, land use and land cover, greatly influence wind profiles at the local scale (Lee et al. 2009; FEMA 2012). However, in most existing studies at the country or global scale, the impact of local factors on TC wind hazards is oversimplified or not considered (Vickery et al. 2000; Arthur et al. 2008; UNISDR 2009, 2011, 2013, 2015). The lack of observations of important TC parameters (Knapp et al. 2010; Landsea and Franklin 2013; Ying et al. 2014) also poses a great challenge to the modeling of wind fields. As a result, there are few TC wind hazard products for the Northwest Pacific (NWP), North Indian (NI), and South Indian (SI) basins that are publicly available, although a few proprietary models have been developed and released in the form of a black box (FIU 2011).

The objective of this study is to map the TC wind hazard at the global scale through parametric wind field models selected for seven ocean basins, which is part of the overall effort to map a variety of global disasters (Shi and Kasperson 2015). The effects of local factors, including topography and surface roughness, are modeled and discussed in detail in this article. Based on the simulated wind fields with historical observed or reconstructed TC parameters, the hazard maps are developed through a statistical analysis of wind intensity and frequency that considers uncertainty.

\section{Datasets}

The main datasets used in this study included the TC best tracks observed by regional meteorological centers (Knapp et al. 2010; Landsea and Franklin 2013; Ying et al. 2014). In the datasets, $\mathrm{TC}$ parameters, including $\mathrm{TC}$ number, time (year, month, day, and hour), locations (longitude and latitude of TC center, lon and lat), central pressure $\left(P_{c}\right)$, maximum wind speed $\left(V_{m}\right)$, and radius of maximum wind speed $\left(R_{m}\right)$, are archived at a time interval of $6 \mathrm{~h}$. The World Meteorological Organization (WMO) has been integrating all TC best track datasets through the International Best Track Archive for Climate Stewardship (IBTrACS) project (Knapp et al. 2010), which may produce inhomogeneities in both temporal and spatial dimensions owing to different data sources (Levinson et al. 2010).

In this study, the TC best track dataset of seven ocean basins are used. Following the quality comparison studies, the China Meteorological Administration (CMA) best track dataset (Ying et al. 2014) for the NWP, the U.S. National Hurricane Center's North Atlantic hurricane database (HURDAT) (Landsea and Franklin 2013) for the North Atlantic (NA), Northeast Pacific (NEP), and Central Pacific (CP), and IBTrACS for the other three basins-NI, South Pacific (SP), and SI, were adopted. The map of archived historical TCs is shown in Fig. 1, and displays storm intensity according to each storm's maximum sustained winds (SAC 2006). For NEP and CP, the TC tracks are usually trans-boundary and cover both basins therefore the two basins are treated as one unit for analysis, as shown in Fig. 1. For South Atlantic (SA) basin, the genesis of TC is very rare (Mctaggart-Cowan et al. 2006) and therefore SA is excluded in this study.

A digital elevation model of the world is needed to reflect the topographic effects on TC winds. In this study, the $1 \mathrm{~km}$ GTOPO30 data (USGS 1996) were selected after being compared with other freely available global digital elevation model (DEM) products, such as the $90 \mathrm{~m}$ Shuttle Radar Topography Mission (SRTM) (Jarvis et al. 2008) and $30 \mathrm{~m}$ Global Digital Elevation Model (GDEM) (ASTER GDEM Validation Team 2011). For wind field modeling, $1 \mathrm{~km}$ is an appropriate resolution owing to the computation resource requirements.

Another dataset for wind field modeling is land use or land cover, which is used to estimate the surface roughness length. In this study, the global land cover classification for 2000 version 2.0 (Loveland et al. 2000), which is based on the USGS Land Use/Land Cover System Scheme (USGS 


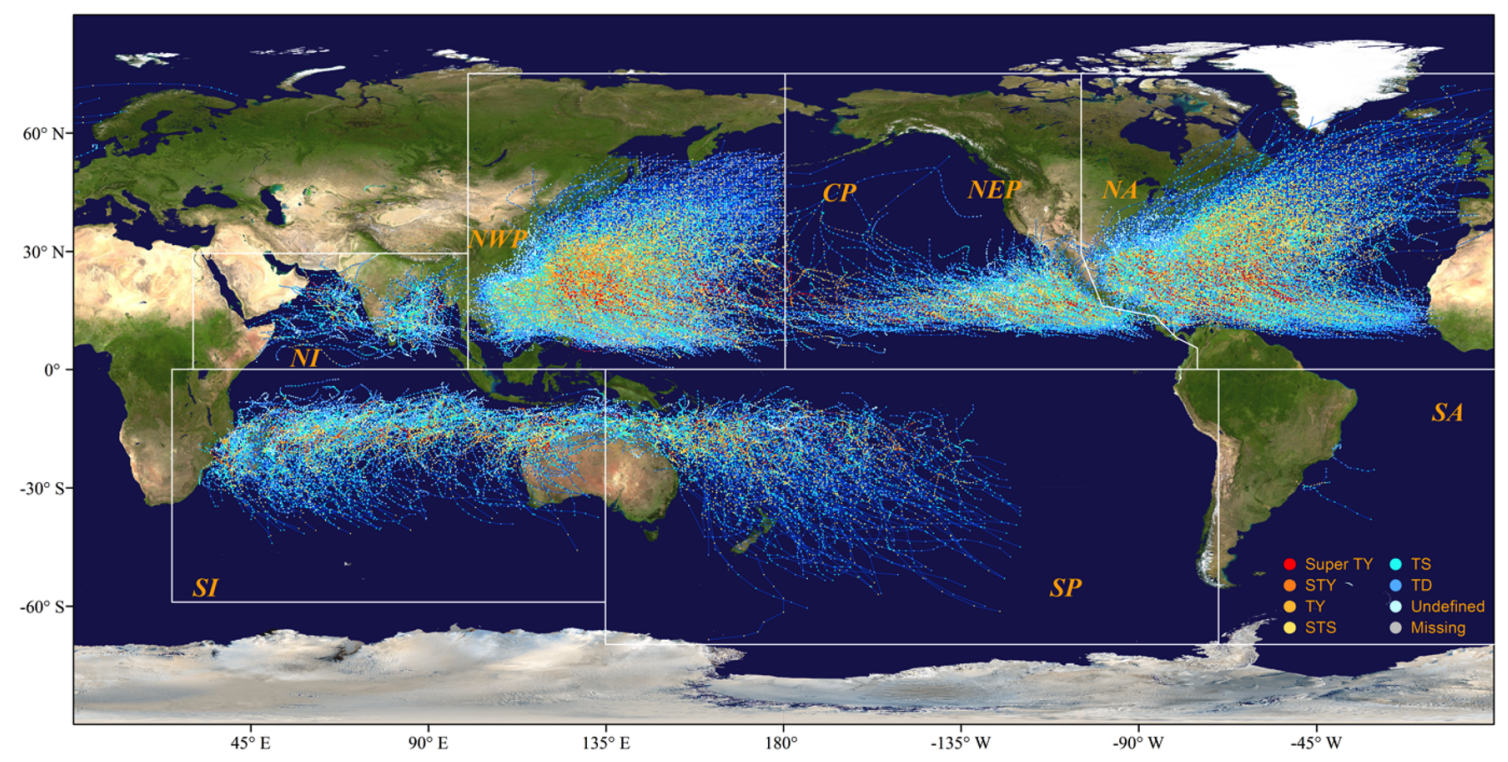

Fig. 1 Global tropical cyclone tracks by ocean basin based on historical TC best track datasets. Note Ocean basins are: NWP Northwest Pacific, NEP Northeast Pacific, CP Central Pacific, NA North Atlantic, SA South Atlantic, NI North Indian, SP South Pacific

2001), was selected to derive global surface roughness lengths because its resolution is identical to that of GTOPO30, and its classification system can be easily matched to that of the empirical roughness length look-up table.

\section{Methods}

In general, parametric wind field models consist of a gradient wind model and a planetary boundary layer (PBL) model (FEMA 2012). The gradient wind can be simulated with observed TC parameters, such as location, intensity, size, moving direction, and speed, which are usually available or can be derived from the TC track dataset. The PBL model converts gradient winds to surface winds at a height of $10 \mathrm{~m}$ by considering the effects of local terrain and surface roughness and therefore helps improve the spatial heterogeneity modeling of wind speed, which is of great importance to wind hazard assessments.

\subsection{Gradient Model}

As the first component of the wind field model, the gradient model simulates the asymmetry of the TC gradient wind field without considering the influence of near-surface terrain. A cyclonic gradient wind is usually considered to be the superposition of two parts: one is the fixed circular symmetry wind field, which can be obtained by the gradient wind balance equation, and the other is the moving and SI South Indian. Tropical cyclone intensities are displayed with six scales: Super TY Super Typhoon, STY Strong Typhoon, TY Typhoon, STS Severe Tropical Storm, TS Tropical Storm and TD Tropical Depression

field associated with the cyclone's forward speed (Chen 1994). It is critical to correctly represent the TC wind field given parameters available from best track data, such as location (lon and lat), intensity $\left(P_{c}\right.$ and $\left.V_{m}\right)$, size $\left(R_{m}\right)$, translation speed $\left(F_{s}\right)$, and direction $\left(F_{d}\right)$ (FEMA 2012).

Because each basin has a different temperature, ambient pressure, and corresponding sources of TC track-intensity data, it is possible to introduce unexpected bias if only one universal model is used for all of the seven basins, as discussed in previous research (UNISDR 2009, 2011). Instead, in this study, a representative model was selected for each basin after reviewing existing models. The models and their input parameters for the seven basins are listed in Table 1 , where $Z_{0}$ is the roughness length, $T_{f}$ is topographic factor, $Z(10 \mathrm{~m})$ is the simulation height, and $P_{n}$ is ambient pressure. The gradient models for NWP, NI, SP, and SI need the modeling of parameter Holland $B$ to reflect the shape of the wind profile, which can be computed with historical data with the methods listed in Table 1. Detailed discussions on Holland B modeling and its empirical value ranges can be found in Lin and Fang (2013).

\subsection{Boundary Model}

In the boundary (near-surface) layer, TCs are strongly influenced by the underlying terrain, which is distinctly different from the sea (Wong and Chan 2007). To assess wind hazard, the PBL model must convert the gradient wind to the near-surface wind. Similar to the gradient 
Table 1 Parametric wind field models for the seven basins and their key parameters

\begin{tabular}{|c|c|c|c|c|}
\hline \multirow[t]{2}{*}{ Basin } & \multirow[t]{2}{*}{ Gradient model } & \multirow[t]{2}{*}{ PBL model } & \multicolumn{2}{|l|}{ Input parameters } \\
\hline & & & Holland B & Other \\
\hline NWP & Georgiou et al. (1983) & Meng et al. (1997) & Vickery and Wadhera (2008) & $P_{c}, R_{m}, P_{n}$, lon, lat $, F_{s}, F_{d}, Z_{0}, T_{f}, Z$ \\
\hline NEP & Willoughby et al. (2006) & Meng et al. (1997) & - & $P_{c}, V_{m}, R_{m}, P_{n}$, lon, lat $, Z_{0}, T_{f}, Z$ \\
\hline $\mathrm{CP}$ & Willoughby et al. (2006) & Meng et al. (1997) & - & $P_{c}, V_{m}, R_{m}, P_{n}$, lon, lat $, Z_{0}, T_{f}, Z$ \\
\hline NA & Willoughby et al. (2006) & Meng et al. (1997) & - & $P_{c}, V_{m}, R_{m}, P_{n}$, lon, lat $, Z_{0}, T_{f}, Z$ \\
\hline NI & Georgiou et al. (1983) & Meng et al. (1997) & Jakobsen and Madsen (2004) & $P_{c}, R_{m}, P_{n}$, lon, lat $, F_{s}, F_{d}, Z_{0}, T_{f}, Z$ \\
\hline SP & McConochie et al. (2004) & Harper (2001) & Harper and Holland (1999) & $P_{c}, R_{m}, P_{n}$, lon, lat $, F_{s}, F_{d}, Z_{0}, T_{f}, Z$ \\
\hline SI & Georgiou et al. (1983) & Meng et al. (1997) & Harper and Holland (1999) & $P_{c}, R_{m}, P_{n}$, lon, lat $, F_{s}, F_{d}, Z_{0}, T_{f}, Z$ \\
\hline
\end{tabular}

Ocean basins are: NWP Northwest Pacific, NEP Northeast Pacific, $C P$ Central Pacific, NA North Atlantic, NI North Indian, SP South Pacific, SI South Indian

models, the PBL models for the seven basins were adopted after reviewing existing studies.

The units used for TC sustained wind speeds may vary by country, ranging from 1-, 2- to 10-min averages. In this study, all sustained winds are converted into 3 -s gust winds according to a past study (ESDU 1983) because gust wind is regarded to have the best statistical relationship with TC damage.

In addition to the TC center (lon and lat), intensity $\left(P_{c}\right.$ and $\left.V_{m}\right)$, and size $\left(R_{m}\right)$, which are available in the best track data, the other main input parameters of the PBL models are terrain roughness $\left(Z_{0}\right)$ and topographic factors $\left(T_{f}\right)$. These parameters can be derived with digital elevation data and land use/cover data.

\subsubsection{Surface Roughness}

The location of zero wind speed in the vertical wind profile, which is defined as the aerodynamic roughness length $\mathrm{Z}_{0}$ (Prigent et al. 2005), is not at the land surface but at a certain height above the surface. According to the PBL model (Meng et al. 1997) used in this study, the vertical wind profile is given by

$\mathrm{U}_{\mathrm{z}}=U_{g}\left(\frac{z}{z_{g}}\right)^{\alpha_{\mathrm{u}}}$

where $U_{z}$ is the wind speed at height $\mathrm{z}, U_{g}$ is the gradient wind speed at the gradient layer height $z_{g}$, and $\alpha_{\mathrm{u}}$ is the power law exponent for the wind speed profile. Both $z_{g}$ and $\alpha_{\mathrm{u}}$ are dependent on $Z_{0}$ and therefore the surface wind speed is heavily influenced by the value of $\mathrm{Z}_{0}$.

For small-scale studies, surface roughness can be determined by direct field observations or wind tunnel tests (Wieringa 1992). For large areas, roughness length is usually estimated from land cover data determined from remote sensing images (Silva et al. 2007; Ramli et al. 2009). Currently, there is no definite standard for categorizing $Z_{0}$ (FEMA 2012). In this study, the relationship between land cover type and empirical roughness length was summarized based on past studies (Wieringa 1992; Davenport et al. 2000; Wieringa et al. 2001; Silva et al. 2007; FEMA 2012). Based on the look-up table shown in Table 2, the global roughness lengths at a resolution of $1 \mathrm{~km}$ grid were estimated from the GLCC data (Loveland et al. 2000), as shown in Fig. 2.

\subsubsection{Topographic Factor}

Complex terrain has a pronounced impact on the nearsurface wind speed, pressure, and turbulence structure. Consequently, the wind fields in these areas exhibit a significant difference from those over flat regions (Ngo and Letchford 2009). An illustrative diagram to display the variations in the vertical wind profiles owing to different terrain features is shown in Fig. 3 based on Davenport et al. (1985), CAPRA (2008), and BSI (2005). According to the figure, there is a great increase in wind speed over hills and cliffs, which is important when modeling wind hazards.

To calculate the local near-surface wind speed more precisely, the surface wind speed over non-flat areas are usually corrected from the modeled wind speed over flat terrain with a topographic factor, $T_{f}$ :

$V_{m}=T_{f} \cdot V_{m f}$

where $V_{m}$ is the mean wind velocity at height $\mathrm{Z}$ above a non-flat terrain and $V_{m f}$ is the mean wind velocity above flat terrain.

The value of $T_{f}$ is usually empirically derived according to terrain type and wind direction. Wind-load codes for the design of building structures, which are usually based on a wide range of theoretical and practical verifications, can be utilized to compute wind speed-up correction. The speedup factors for different building codes may vary due to 
Table 2 Look-up table for the surface roughness length and the USGS Land Use / Land Cover System

\begin{tabular}{|c|c|c|c|c|c|}
\hline Code & Type & $Z_{0}(\mathrm{~m})$ & Code & Type & $Z_{0}(\mathrm{~m})$ \\
\hline 1 & Urban and built-up land & 1.2 & 13 & Evergreen broadleaf forest & 0.75 \\
\hline 2 & Dryland cropland and pasture & 0.05 & 14 & Evergreen needleleaf forest & 0.75 \\
\hline 3 & Irrigated cropland and pasture & 0.05 & 15 & Mixed forest & 0.75 \\
\hline 4 & Mixed dryland/irrigated cropland and pasture & 0.05 & 16 & Water bodies & 0.0003 \\
\hline 5 & Cropland/grassland mosaic & 0.05 & 17 & Herbaceous wetland & 0.01 \\
\hline 6 & Cropland/woodland mosaic & 0.6 & 18 & Wooded wetland & 0.03 \\
\hline 7 & Grassland & 0.03 & 19 & Barren or sparsely vegetated & 0.03 \\
\hline 8 & Shrubland & 0.6 & 20 & Herbaceous tundra & 0.01 \\
\hline 9 & Mixed shrubland/grassland & 0.3 & 21 & Wooded tundra & 0.01 \\
\hline 10 & Savanna & 0.3 & 22 & Mixed tundra & 0.01 \\
\hline 11 & Deciduous broadleaf forest & 0.75 & 23 & Bare ground tundra & 0.01 \\
\hline 12 & Deciduous needleleaf forest & 0.75 & 24 & Snow or ice & 0.001 \\
\hline
\end{tabular}

$Z_{0}$ measures aerodynamic roughness length; Holland B reflects the shape of the wind profile; planetary boundary layer (PBL) models explicitly integrate local effects at $1 \mathrm{~km}$ resolution

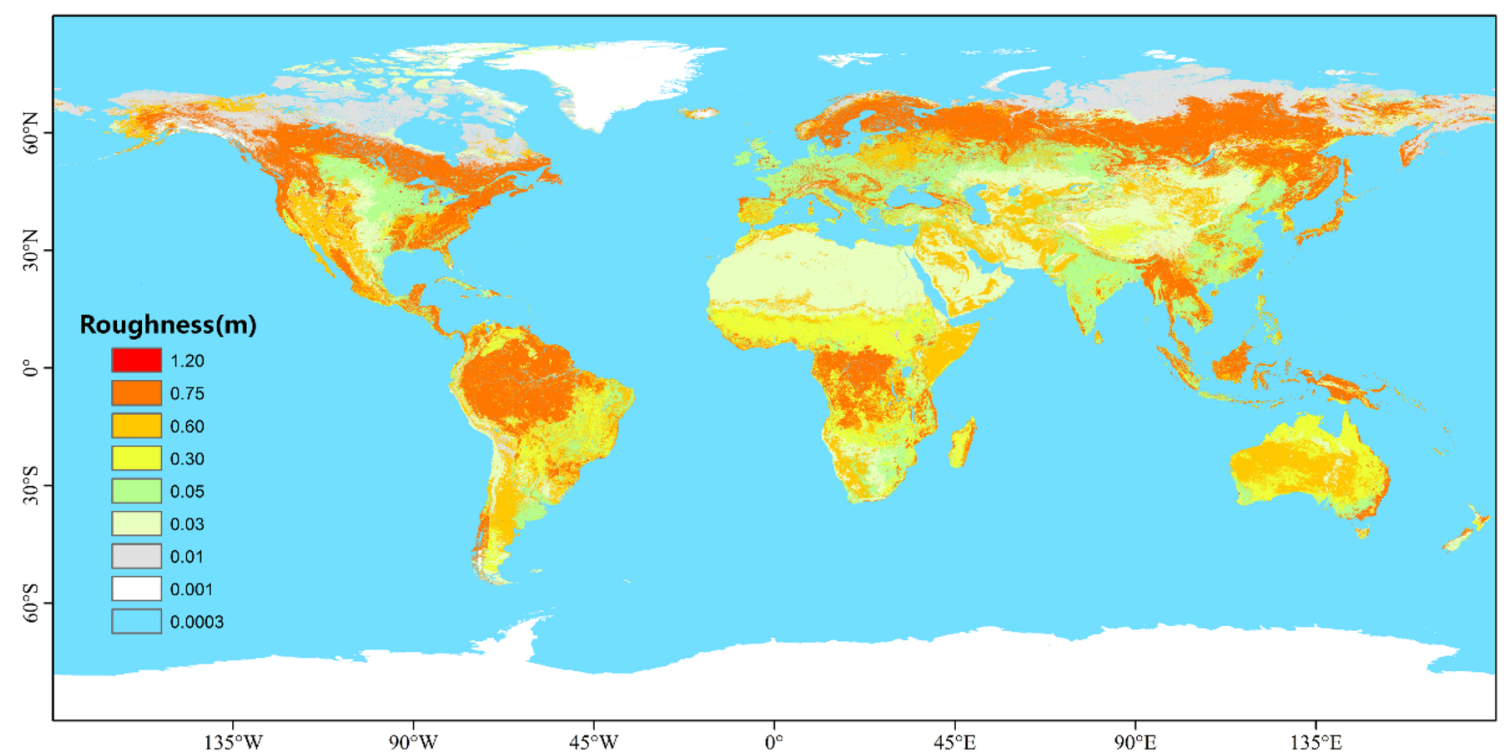

Fig. 2 Global roughness length estimated from GLCC data based on the USGS Land Use / Land Cover System

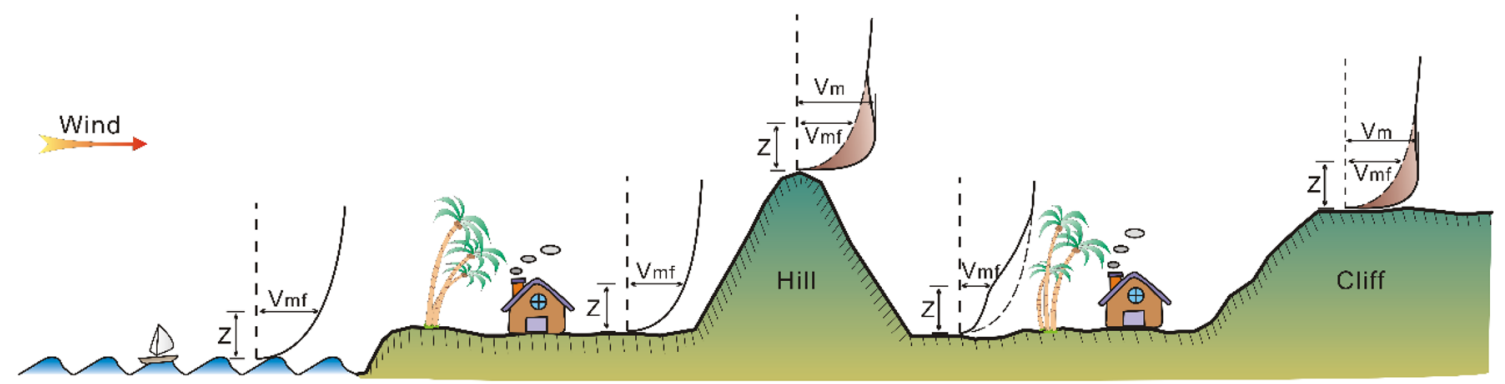

Fig. 3 Illustrative diagram of wind speed variations caused by topographic effects. Note $Z(10 \mathrm{~m})$ is the simulation height; $V_{m f}$ is the mean wind velocity above flat terrain; and $V_{m}$ is the mean wind velocity at height $Z$ 
their different degrees of terrain simplification (Maharani et al. 2009).

After a systematic comparison of the codes of Europe (BSI 2005), the United States (ASCE 2006), Japan (AIJ 2004), China (CECS 2006), and Australian / New Zealand (Standards Australia / Standards New Zealand 2002), we selected the European standard for its detailed speed-up factor computation method and complete terrain classification. According to the standard, terrain features are categorized into ground, cliff (or escarpment), hill (or ridge), and valley, and the technical details for deriving the speedup factors can be found in Annex A.3 of BSI (2005).

The methods in the building codes were originally developed for construction design at specific sites where the terrain type can be easily observed and determined. In this study, we combine mesoscale wind field modeling with microscale speed-up modifications by considering topographic factors. To compute automatically the speed-up factors of all pixels, a GIS algorithm was developed to determine the type of terrain feature for every pixel in the world at eight wind directions. According to the algorithm, a given TC wind direction is within the $22.5^{\circ}$ sector on both sides of a certain prevailing wind direction. For a given pixel, if its windward slope is greater than $0.05^{\circ}$ and its leeward slope is less than $0.05^{\circ}$, it is classified as a cliff. When both are greater than $0.05^{\circ}$, it is defined as a hill. Otherwise, the pixel is regarded as ground or valley with a topographic factor of 1.0. As an example, the topographic factors at $1 \mathrm{~km}$ resolution for the eight directions over Hainan Island $\left(108^{\circ}-111^{\circ} \mathrm{E}, 18^{\circ}-20^{\circ} \mathrm{N}\right)$, China, are displayed in Fig. 4 based on GTOPO30 DEM data.

\subsection{Estimation of Missing TC Parameters}

The values of $P_{c}$ and $V_{m}$, especially of $R_{m}$, are not available in some TCs of the best track datasets. Previous research has shown that there is a significant statistical relationship between the TC central pressure difference $(\Delta P)$ and $V_{m}$ in the form of $V_{m}=A\left(P_{n}-P_{c}\right)^{B}$, in which $\Delta P$ is the difference between the environmental pressure $\left(P_{n}\right)$ and the TC central pressure $\left(P_{c}\right)$, and $A$ and $B$ are fitting constants (Takahashi 1939; Atkinson and Holliday 1977; Harper 2002). The average ambient pressure, $P_{n}$, may vary by several hPa in the seven basins; based on past studies, $P_{n}$ in NI was set to $1013.25 \mathrm{hPa}$ (Islam and Peterson 2008), in NA, NEP, and CP was set to $1013 \mathrm{hPa}$ (Landsea et al. 2004), and in the other three basins was set to $1010 \mathrm{hPa}$ (Atkinson and Holliday 1977; Holland 2008). Based on the existing records in the best track datasets, the fitted relations between $V_{m}$ and $P_{c}$ and their coefficients for the seven basins are established (Table 3 ).

The values of $R_{m}$ for most TCs did not exist in most historical records until observations became available in 2001 (Knapp et al. 2010). In this study, the empirical functions of $R_{m}$ to other TC variables $\left(P_{n}\right.$ and lat) in the seven basins were obtained from existing studies (Vickery and Wadhera 2008; FEMA 2012). For the NWP, NI, SP, and SI, the values of $R_{m}$ were estimated based on the Joint Typhoon Warning Center (JTWC) dataset as integrated into IBTrACS. Whereas for the NA, NEP, and CP basins, past research results were used (Vickery and Wadhera 2008). The percentages of missing parameters from the best track datasets and the equations for estimating $R_{m}$ are listed in Table 3, in which a high percentage of missing $P_{c}$ values in the NA was caused by a lack of measurements before the 1950s.
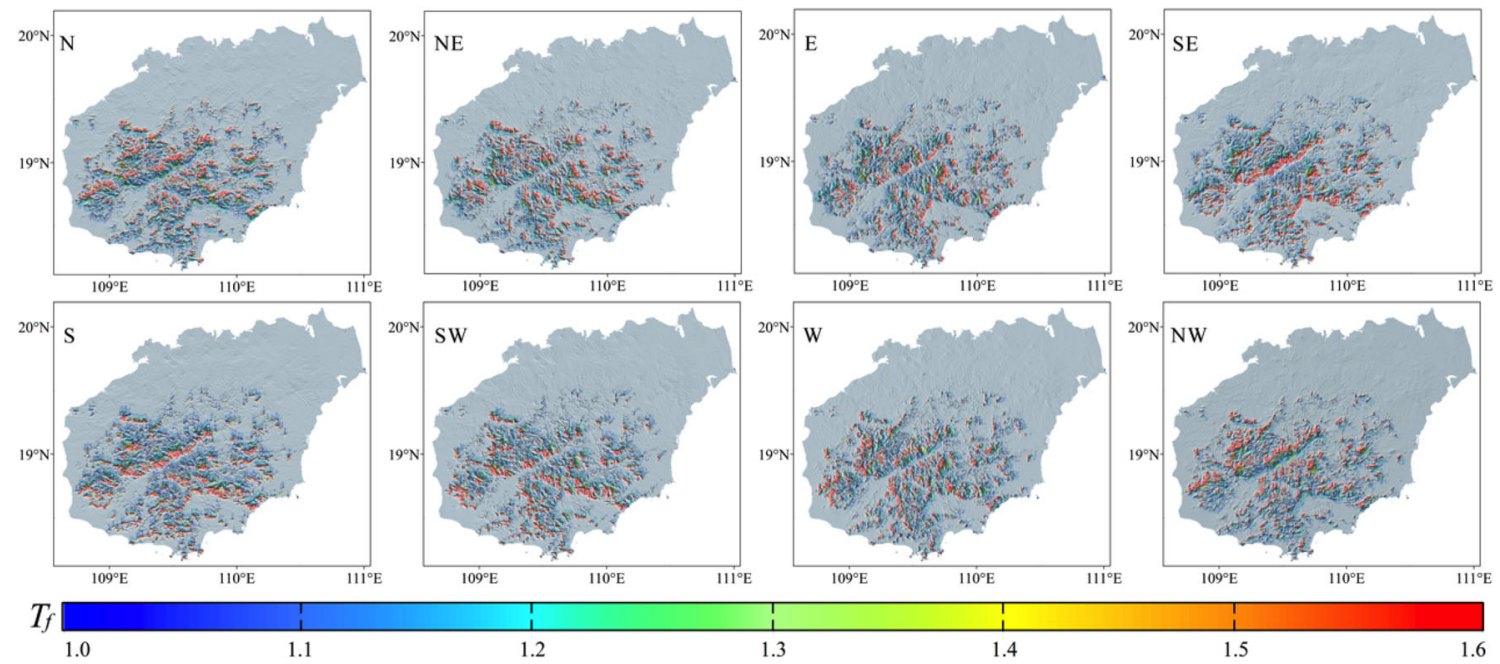

1.2

1.3

1.4

1.5

Fig. 4 Terrain speed-up factors for Hainan Island, China, for eight wind directions 
Table 3 Empirical wind speed-TC central pressure relationships and fitting equations of $\boldsymbol{R}_{\boldsymbol{m}}$ in the seven basins

\begin{tabular}{|c|c|c|c|c|c|c|}
\hline \multirow[t]{2}{*}{ Basin } & \multicolumn{2}{|c|}{ Missing parameters $(\%)$} & \multicolumn{3}{|c|}{ Estimated constants } & \multirow[t]{2}{*}{ Estimation of $R_{m}$} \\
\hline & $V_{m}(\%)$ & $P_{c}(\%)$ & $P_{n}$ & $A$ & $B$ & \\
\hline NWP & 9.18 & 0.00 & 1010.00 & 2.607 & 0.751 & $R_{m}=-18.29 \ln \left(1010-P_{c}\right)+113.23$ \\
\hline NEP & 0.00 & 51.97 & 1013.00 & 5.278 & 0.574 & $R_{m}=\exp \left(3.015-6.291 \times 10^{-5}\left(1013-P_{c}\right)^{2}+0.0337\right.$ lat $)$ \\
\hline $\mathrm{CP}$ & 0.00 & 70.07 & 1013.00 & 5.381 & 0.571 & $R_{m}=\exp \left(3.015-6.291 \times 10^{-5}\left(1013-P_{c}\right)^{2}+0.0337\right.$ lat $)$ \\
\hline NA & 0.71 & 63.55 & 1013.00 & 5.466 & 0.566 & $R_{m}=\exp \left(3.015-6.291 \times 10^{-5}\left(1013-P_{c}\right)^{2}+0.0337\right.$ lat $)$ \\
\hline $\mathrm{NI}$ & 0.00 & 68.56 & 1013.25 & 2.248 & 0.742 & $R_{m}=-26.73 \ln \left(1013.25-P_{c}\right)+142.41$ \\
\hline $\mathrm{SP}$ & 11.29 & 0.07 & 1010.00 & 2.347 & 0.727 & $R_{m}=-22.31 \ln \left(1010-P_{c}\right)+126.50$ \\
\hline SI & 16.20 & 3.20 & 1010.00 & 2.753 & 0.677 & $R_{m}=-18.82 \ln \left(1010-P_{c}\right)+111.95$ \\
\hline
\end{tabular}

Ocean basins are: Northwest Pacific (NWP); Northeast Pacific (NEP); CP (Central Pacific); NA (North Atlantic); NI (North Indian); SP (South Pacific); SI (South Indian). Tropical storm parameters include mean wind velocity $\left(V_{m}\right)$, environmental pressure $\left(P_{n}\right)$, central pressure $\left(P_{c}\right)$, and storm wind field size $\left(R_{m}\right)$, while $\mathrm{A}$ and $\mathrm{B}$ are fitting constants

To reflect temporal changes in wind, the simultaneous wind fields of a TC can be simulated over short temporal intervals, such as 10 or $15 \mathrm{~min}$. In this study, all parameters in the best track datasets were linearly interpolated to $10 \mathrm{~min}$ ( $\mathrm{Li}$ et al. 2014). The TCs selected in this work included all land-falling TCs and all bypassing TCs with a gradient wind exceeding $5.5 \mathrm{~m} / \mathrm{s}$ over land (terrain and roughness effects were not considered); TCs with no influence on land were excluded from simulation (Table 4).

\subsection{Wind Field Validation}

Based on the above wind field models, the instantaneous wind field, which is referred to as a snapshot, at any specific time can be simulated, and the maximum of all snapshots can be derived for each TC (called a footprint). In this study, the footprints of historical TC events (Table 4) were computed based on the simulated snapshots at 10-min intervals, including the strongest 3-s gust wind and both 2 - and 10-min sustained winds.
The gradient models used in this study have been widely validated in NA (Willoughby et al. 2006), NEP (Willoughby et al. 2006), and SP (McConochie et al. 2004), as well as the PBL model in SP. For NWP, NI, and SI, the same PBL models were chosen to simulate the wind field basin as listed in Table 1. Few local, validated studies based on these models are available in NWP, NI, and SI.

To show the performance of the models used in the NWP, the modeled winds were compared with groundbased wind observations in China. The wind observation data were obtained from ground weather stations. The modeled and observed time series of 10-min sustained winds for four strong TCs making landfall in China are plotted in Fig. 5. To understand the overall accuracy of the maximum wind time series, the observed and modeled maximum 10-min sustained winds and 3-s gust winds are plotted in Fig. 6 based on the observed daily maximum winds for 36 TCs during the period 1970-2014 from 25 stations located in Hainan Island, China.

Table 4 Statistics for the simulated global tropical cyclone best track datasets by basin

\begin{tabular}{|c|c|c|c|c|c|c|c|}
\hline \multirow[t]{2}{*}{ Basin } & \multirow[t]{2}{*}{ Data Source } & \multirow[t]{2}{*}{ Duration } & \multicolumn{4}{|c|}{ Number of TCs } & \multirow[t]{2}{*}{ Simulated snapshots } \\
\hline & & & Landfall & Bypassing & Not simulated & Total & \\
\hline NWP & CMA and IBTrACS & 1949-2014 & 1340 & 701 & 192 & 2233 & $2,101,692$ \\
\hline NEP & HURDAT & 1949-2012 & 170 & 471 & 273 & 914 & 551,670 \\
\hline $\mathrm{CP}$ & HURDAT & 1950-2012 & 3 & 29 & 30 & 62 & 37,508 \\
\hline NA & HURDAT & $1851-2012$ & 1068 & 513 & 132 & 1713 & $1,542,086$ \\
\hline NI & IBTrACS & $1972-2012$ & 147 & 49 & 0 & 196 & 143,420 \\
\hline $\mathrm{SP}$ & IBTrACS & 1970-2012 & 175 & 255 & 9 & 439 & 407,734 \\
\hline SI & IBTrACS & 1973-2012 & 160 & 295 & 92 & 547 & 549,851 \\
\hline
\end{tabular}

Ocean basins are: NWP Northwest Pacific, NEP Northeast Pacific, $C P$ Central Pacific, NA North Atlantic, NI North Indian, SP South Pacific, SI South Indian. Data sources include: CMA China Meteorological Administration, IBTrACS International Best Track Archive for Climate Stewardship, and HURDAT U.S. National Hurricane Center's North Atlantic hurricane database 

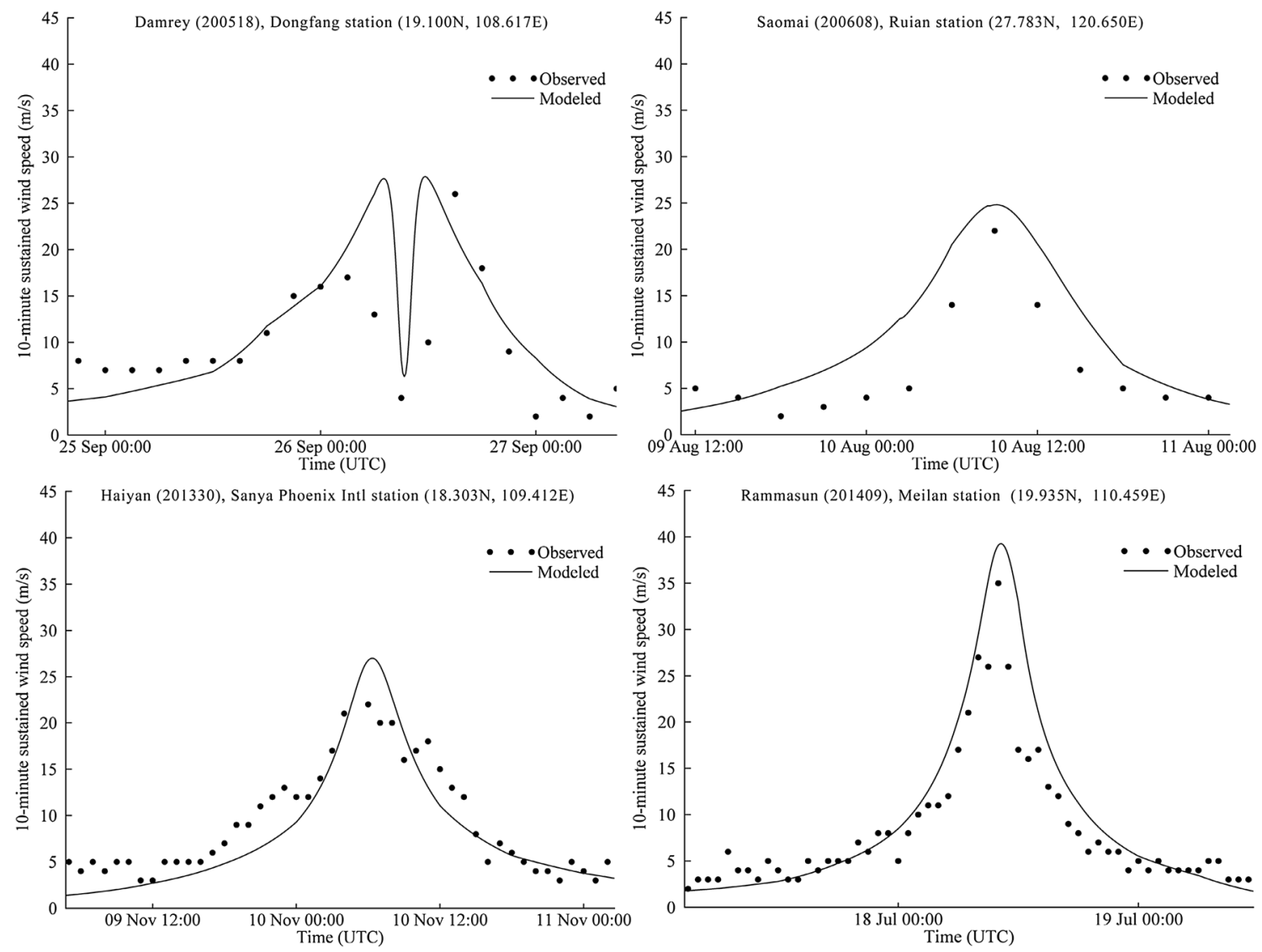

Fig. 5 Modeled and observed 10-min sustained wind time series for four TCs in the Northwest Pacific (NWP) basin
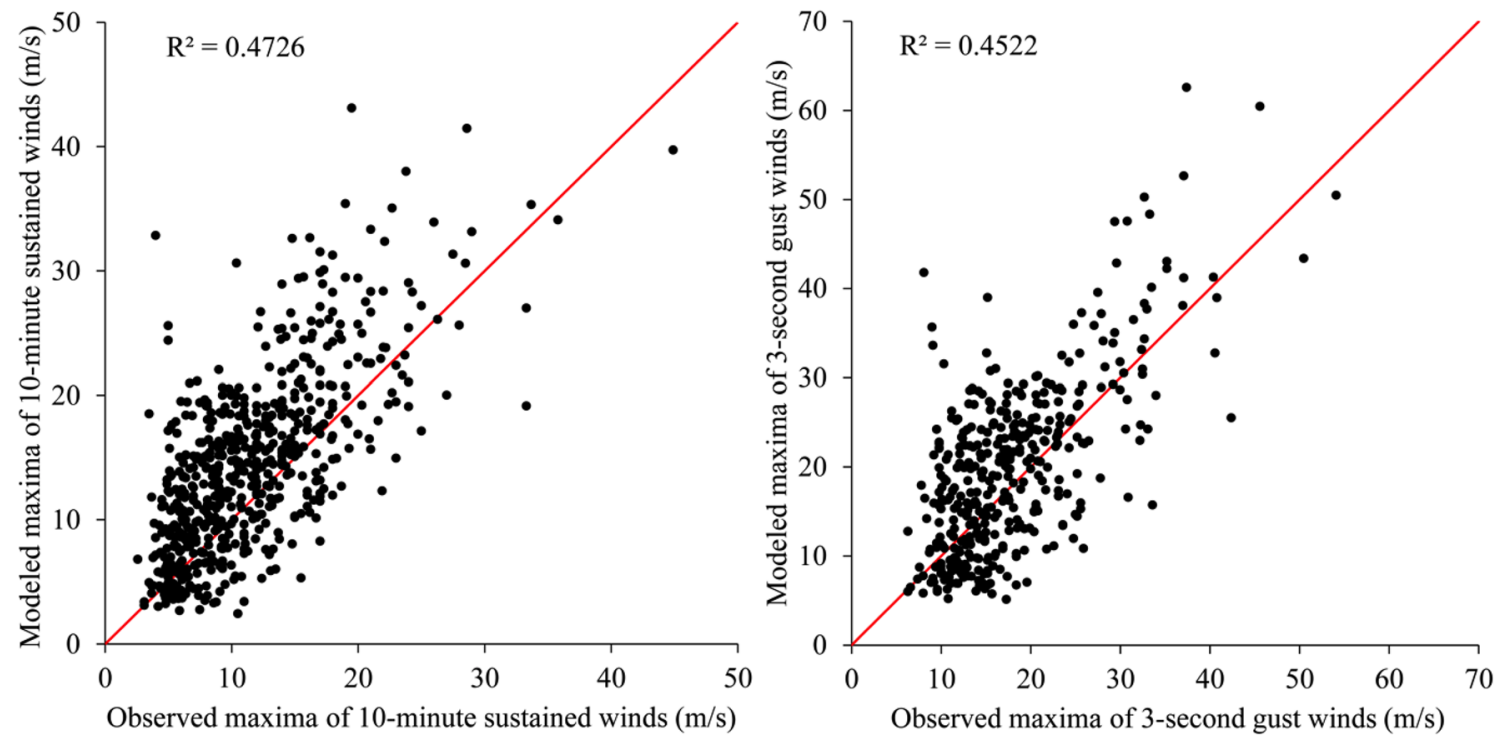

Fig. 6 Modeled and observed maximum 10-min sustained winds and 3-s gust winds of 36 TCs during 1970-2014 for 25 stations in Hainan Island, China

Figure 5 shows that the shapes of the simulated and observed wind speed time series agree well, and their maximum values are similar, which means that the TC wind time series is well captured by the models. The scatterplots shown in Fig. 6 display a statistically significant correlation between the simulated and observed maximum wind speeds. 

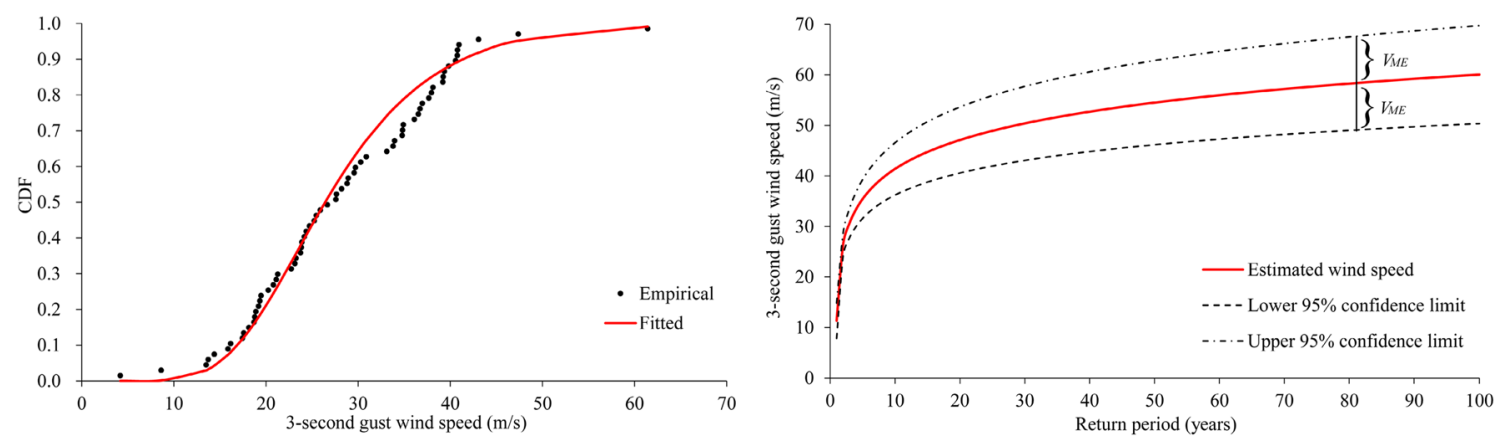

Fig. 7 Cumulative distribution functions and wind frequency for Meilan station in Hainan Province, China

Bias in these parametric models might be introduced from a range of factors. One of the major reasons that our wind field modeling may not be realistic is that one of the key local factors-land use/cover-was kept constant using global land cover data from year 2000 only, instead of using data corresponding to each year. In addition, errors may also be introduced owing to inaccurate or insufficient resolution of the input data and limited model skill.

\subsection{Wind Hazard Analysis}

The generalized extreme value (GEV) theory is often applied to quantify the relationship between the intensity and frequency of extreme natural events (Goldstein et al. 2008). The Gumbel distribution is usually selected for wind distribution fitting (Rupp and Lander 1996; An and Pandey 2005; BSI 2005); its cumulative distribution function $(\mathrm{CDF})$ is

$\mathrm{F}(x, \xi, \theta)=\exp \{-\exp [-(x-\xi) / \theta]\}$

where the scale parameter is $\theta$ and the location parameter is $\xi$. We obtain the moment estimates of $\theta$ and $\xi$ as $\hat{\theta}=$ $\sqrt{6} S / \pi$ and $\hat{\xi}=\bar{X}-\gamma \hat{\theta}$, and $\gamma$ is Euler's constant (0.577216) (Tiago de Oliveira 1963). In this study, $\bar{X}$ and $S$ are the mean and standard deviation of the annual maximum TC wind speed, which can be derived from the time series of the simulated historical footprints. The wind speeds for a $T$-year return period can be estimated using

$V_{T}=\hat{\xi}-\hat{\theta} \ln [-\ln (1-1 / T)]$

In addition to the expected wind speeds at specific return periods, the uncertainty in the estimations is of great importance for understanding and applying wind hazard maps. In this study, uncertainty was quantified via a confidence test. The margin of error at the $95 \%$ confidence interval (CI) of wind speeds for a $T$-year return period can be expressed by
$\mathrm{V}_{M E}=Z_{\alpha / 2} \sqrt{\operatorname{Var}(\hat{\xi})+\operatorname{Var}(\hat{\theta})\{\ln [-\ln (1-1 / T)]\}^{2}-2\{\ln [-\ln (1-1 / T)]\} \operatorname{Cov}(\hat{\xi}, \hat{\theta})}$

where $1-\alpha, 0.95$ is the significance level, and $Z_{\alpha / 2}$ is the upper $\alpha / 2$ quantile of standard normal distribution estimated as 1.96. Variances in $\hat{\xi}$ and $\hat{\theta}$ are expressed by $\operatorname{Var}(\hat{\xi})$ and $\operatorname{Var}(\hat{\theta})$ estimated as $1.1678 \theta^{2} / \mathrm{n}$ and $1.1 \theta^{2} / \mathrm{n}$, and the covariance of $\hat{\xi}$ and $\hat{\theta}$ is $\operatorname{Cov}(\hat{\xi}, \hat{\theta})$ estimated as $0.1229 \theta^{2} / \mathrm{n}$. The relative uncertainty in the wind hazard estimation can be expressed as

$V_{R E}=\mathrm{V}_{M E} / \mathrm{V}_{T} \times 100 \%$

Taking Meilan station (19.935 N, 110.459 E) in Hainan Province, China as an example, a total of 66 annual maximum TC winds can be obtained from the modeled wind fields. The empirical and fitted CDFs and the wind frequency for Meilan station are plotted in Fig. 7. In order to reflect the goodness of fitting, the Kolmogorov-Smirnov test (K-S test) was conducted and the results are presented in Sect. 4.2.

\section{Results}

In this section, the simulated wind fields of 10 devastative TCs are presented to demonstrate the effects of local topographic and roughness factors. Following that, global TC wind hazard mapping results are illustrated by displaying a100-year return period wind hazard map and its relative uncertainty. The $\mathrm{K}-\mathrm{S}$ test result for quantifying goodness of GEV fitting is provided as well.

\subsection{Simulated Wind Fields}

In this study, for the seven ocean basins, 5,333,961 snapshots and 5376 footprints were simulated. To present the simulated TC wind fields, the snapshots at landfall and footprints of representative TCs are shown in Fig. 8 for 
Fig. 8 Simulated snapshots and footprints (3-s gust wind for 10 representative devastative TCs) in the Northwest Pacific, North Atlantic, North Indian, South Pacific, and South Indian Ocean Basins
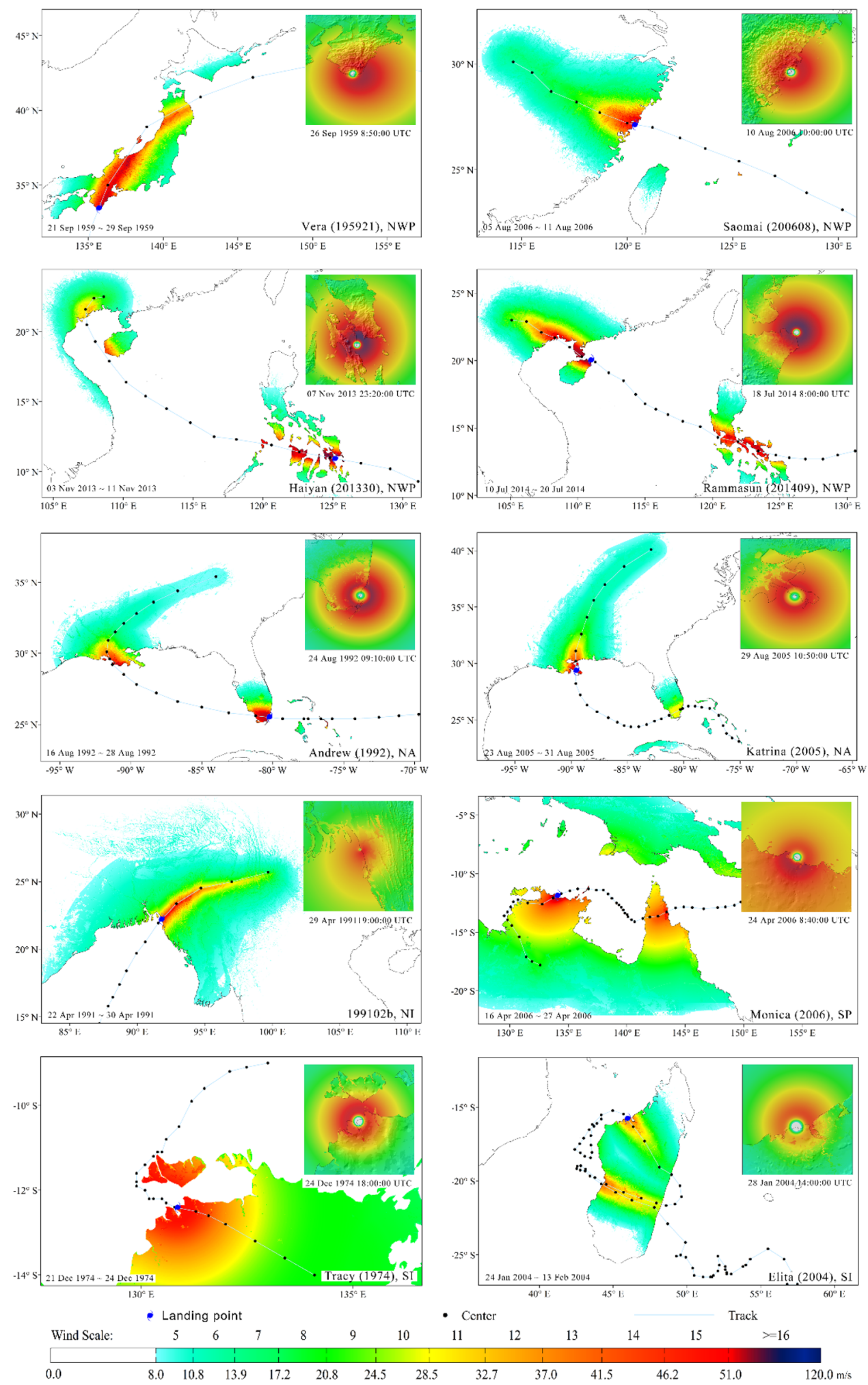

In the intuitive illustration of snapshots and footprints in Fig. 8, the key characteristics of the wind fields are well captured. The spatial heterogeneity of the wind fields is quantified by the PBL models by consideration of the variations in terrain type, slope direction, slope degree, and
Vera, Saomai, Haiyan, and Rammasun in NWP; Andrew and Katrina in NA; one unnamed TC in NI; Monica in SP; and Tracy and Elita in SI. These devastating TCs caused great casualties and economic losses in many affected countries (Guha-Sapir et al. 2013). 

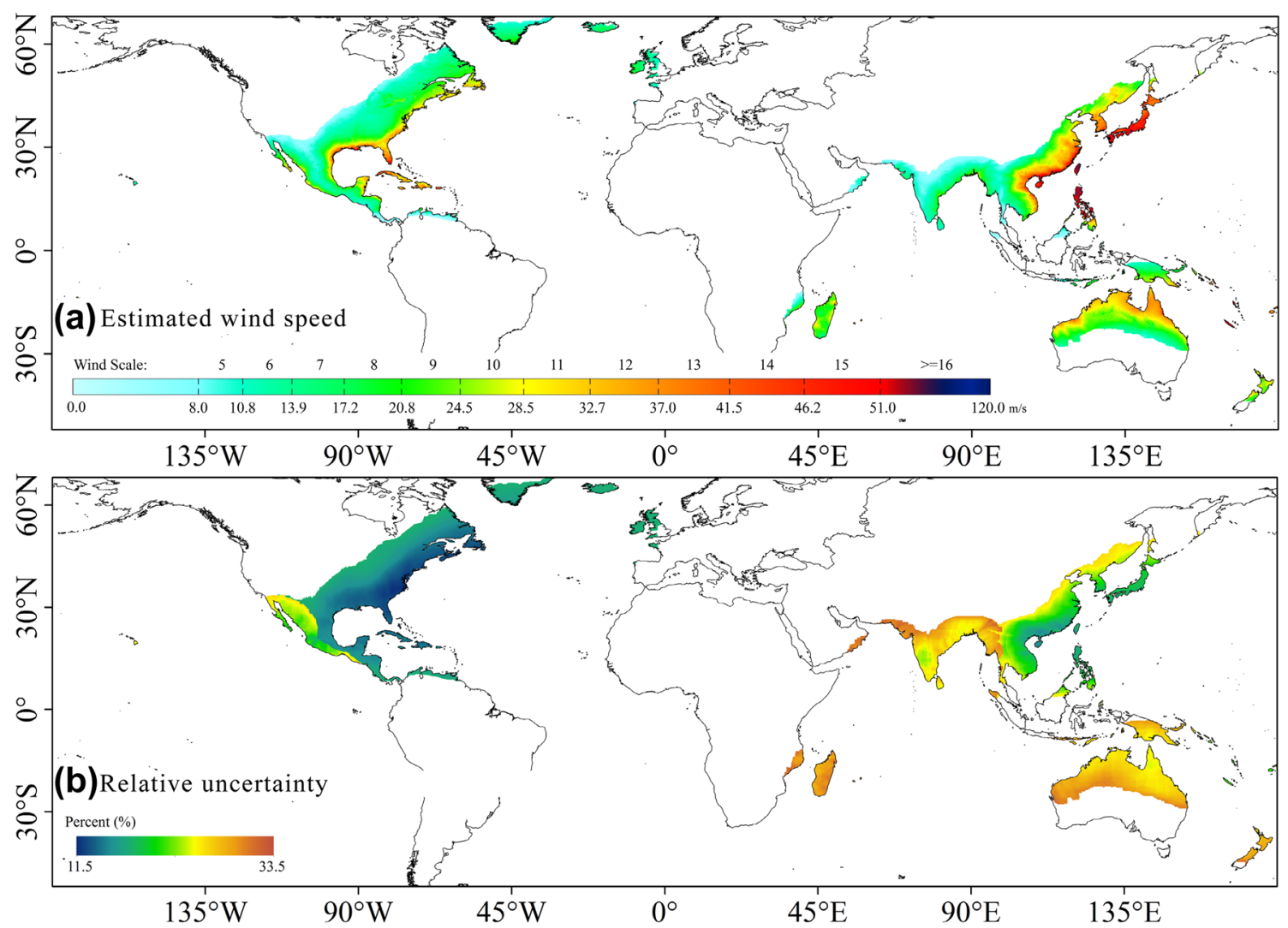

Fig. 9 Global TC wind hazard map at $1 \mathrm{~km}$ resolution (3-s gust winds for a 100-year return period) in seven ocean basins

Fig. 10 Maximum difference (D) of the KolmogorovSmirnov (K-S) test for goodness-of-fit in tropical storm-impacted areas of seven ocean basins

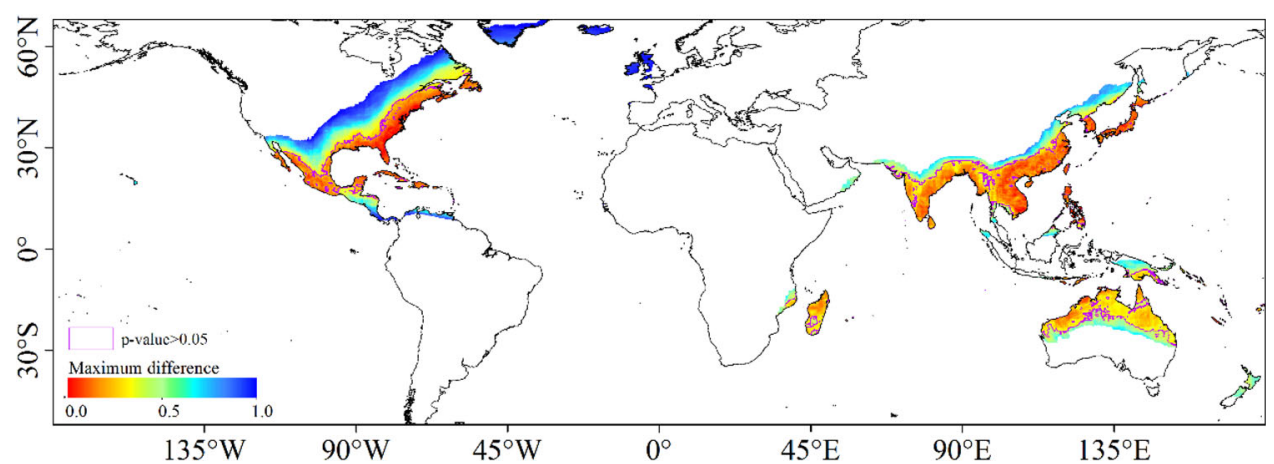

surface roughness length. Moreover, there is a distinct difference between the winds over the sea and land, which is usually caused by the rapid decay of TCs after landfall. Asymmetry in the simulated instantaneous wind fields are captured because the gradient models are able to integrate the effect of TC forwarding.

\subsection{Wind Hazard Maps}

Based on the historical time series of simulated wind fields and the GEV methods employed, the wind speeds for any return period and the corresponding uncertainty can be estimated. In this article, a global wind hazard map is presented in Fig. 9a for 3-s gust wind speeds with a return period of 100 years. The relative uncertainty in the wind hazard estimation is shown in Fig. 9b.

In addition to the extensively studied areas over NA, Australia, and Central America, the TC hazard intensity in the NWP and NI basins are also strong. Moreover, according to Fig. 9b, the uncertainty is greater in inland areas, where there are fewer historical TC samples.

As shown in Fig. 10, most of the extreme wind speeds in coastal areas passed $95 \%$ confidence level test. Although the inland areas are generally less significant, the errors have less impact since their absolute severities are much lower. 


\section{Conclusion}

The development of TC wind hazard maps is of great importance to disaster mitigation, especially for less developed and disaster-prone areas. In the past, most TC wind hazard maps were created for developed areas, and few maps have been developed with detailed consideration of local effects at the global scale. In this study, we mapped the global TC wind hazard by explicitly considering local topographic and roughness factors at $1 \mathrm{~km}$ resolution with locally validated models and reconstructed TC parameters. The major improvements include the reconstruction of key TC track parameters, the detailed consideration of local factors in PBL modeling, and the explicit representation of hazard uncertainty.

Existing TC wind hazard research has mainly focused on local-scale modeling and mapping. Although there are several published TC wind hazard maps at the global scale, in these studies, the local factors that are critical for representing local wind heterogeneity were not considered in detail. The main improvement in this study compared to existing research is that it explicitly integrated both topographic factors (terrain type, slope, and aspect) and roughness factors (land use and land cover) at $1 \mathrm{~km}$ resolution into the PBL models. The topographic factors for eight wind directions were derived based on the European Standard, and roughness lengths were estimated based on global land cover maps. The verification results showed that the simulated wind speeds agree well with the observed values.

The absence of key TC track-intensity parameters, such as $P_{c}, V_{m}$, and $R_{m}$, in some records means that they must be reconstructed prior to the simulation of the wind fields. In this study, we estimated the missing parameters based on empirical regression functions by basin instead of using a general function.

Quantitative TC wind hazard assessments help clarify the spatial distribution and identify regions of high TC wind hazard. The TC wind hazard map for a 100-year return period was produced with its relative uncertainties. This map provides a more comprehensive understanding of wind hazards for decision makers. The hazard maps produced in this study have been tentatively applied in disaster prevention and mitigation in China and the Philippines, especially for the insurance industry and government agencies.

There is still space for future improvement in the field of TC wind hazard assessment. First, the accuracy and reliability of TC input parameters and data could be improved. For example, the empirical functions for estimating missing parameters should be continually improved as more observed data become available, and higher-resolution data, such as GDEM (ASTER GDEM Validation Team 2011), which are capable of generating more accurate local factors, should be utilized. Second, local factors can be obtained not by following the empirical value in the building codes but by detailed numerical modeling based on computational fluid dynamics (Yan et al. 2013) or wind tunnel experiments (Chock and Cochran 2006). Third, to reduce the uncertainty due to the lack of observed TC samples, stochastic modeling of TC tracks may be employed to improve the reliability of assessment results (Vickery et al. 2000; Fang and Lin 2013).

Acknowledgements This work is supported by the National Key Research and Development Program of China (No. 2017YFA0604903). We would like to thank the three anonymous reviewers for their constructive comments and suggestions.

Open Access This article is distributed under the terms of the Creative Commons Attribution 4.0 International License (http://crea tivecommons.org/licenses/by/4.0/), which permits unrestricted use, distribution, and reproduction in any medium, provided you give appropriate credit to the original author(s) and the source, provide a link to the Creative Commons license, and indicate if changes were made.

\section{References}

AIJ (Architectural Institute of Japan). 2004. Recommendations for loads on buildings. Tokyo, Japan: AIJ.

An, Y., and M.D. Pandey. 2005. A comparison of methods of extreme wind speed estimation. Journal of Wind Engineering and Industrial Aerodynamics 93(7): 535-545.

Arthur, C., A. Schofield, B. Cechet, and A. Sanabria. 2008. Return period cyclonic wind hazard in the Australian region. In Proceedings of the 28th AMS Conference on Hurricanes and Tropical Meteorology, 28 April-2 May 2008, Orlando, FL, USA. https://ams.confex.com/ams/pdfpapers/138556.pdf. Accessed 18 Aug 2017.

ASCE (American Society of Civil Engineers). 2006. Minimum design loads for buildings and other structures, SEI/ASCE 7-05. Reston, Virginia: ASCE.

ASTER GDEM Validation Team. 2011. ASTER global digital elevation model version 2-Summary of validation results. http://www.jspacesystems.or.jp/ersdac/GDEM/ver2Validation/ Summary_GDEM2_validation_report_final.pdf. Accessed 12 Aug 2017.

Atkinson, G.D., and C.R. Holliday. 1977. Tropical cyclone minimum sea level pressure/maximum sustained wind relationship for the Western North Pacific. Monthly Weather Review 105(4): 421-427.

BSI (British Standards Institution). 2005. Eurocode 1: Actions on structures - General actions - Part 1-4: Wind actions. Brussels, Belgium: European Committee for Standardization.

CAPRA (Comprehensive Approach to Probabilistic Risk Assessment Initiative). 2008. ERN-hurricane english tutorial. http://ecapra. org/sites/default/files/static/Huracan/english/player.html. Accessed 1 Dec 2013.

Cardona, O.D., M.G. Ordaz, E. Reinoso, L.E. Yamín, and A.H. Barbat. 2012. CAPRA - Comprehensive approach to probabilistic risk assessment: International initiative for risk management effectiveness. In Proceedings of the 15th World Conference on 
Earthquake Engineering, 24-28 September 2012, Lisbon, Portugal. http://www.iitk.ac.in/nicee/wcee/article/WCEE2012_ 0726.pdf. Accessed 18 Aug 2017.

CECS (China Association for Engineering Construction Standardization). 2006. Load code for design of building structures GB50009-2001. Beijing: China Architecture and Building Press (in Chinese).

Chen, K. 1994. A computation method for typhoon wind field. Tropical Oceanology 13(2): 41-48 (in Chinese).

Chock, G.Y.K., and L. Cochran. 2006. Erratum to "Modeling of topographic wind speed effects in Hawaii": [Journal of Wind Engineering \& Industrial Aerodynamics: Volume 93, issue 8, August 2005, pp. 623-638]. Journal of Wind Engineering and Industrial Aerodynamics 94(3): 173-187.

CIMNE (International Centre for Numerical Methods in Engineering). 2013. Probabilistic modeling of natural risks at the global level: Global risk model. Geneva: UNISDR.

Davenport, A.G., P.N. Georgiou, and D. Surry. 1985. A hurricane wind risk study for the Eastern Caribbean, Jamaica and Belize, with special consideration to the influence of topography. London and Ontario, Canada: Boundary Layer Wind Tunnel Laboratory and Faculty of Engineering Science, University of Western Ontario.

Davenport, A.G., C.S.B. Grimmond, T.R. Oke, and J. Wieringa. 2000. Estimating the roughness of cities and sheltered country. In Proceedings of the 12th Conference on Applied Climatology, 8-11 May 2000, American Meteorological Society, Asheville, North Carolin, USA, 96-99.

Elsner, J.B., T.H. Jagger, and K.-B. Liu. 2008. Comparison of hurricane return levels using historical and geological records. Journal of Applied Meteorology and Climatology 47(2): 368-374.

Emanuel, K., S. Ravela, E. Vivant, and C. Risi. 2006. A statistical deterministic approach to hurricane risk assessment. Bulletin of the American Meteorological Society 87(3): 299-314.

ESDU (Engineering Sciences Data Unit). 1983. Strong winds in the atmospheric boundary layer. Part 2: Discrete gust speeds, ESU83045. London: ESDU.

Fang, W., and W. Lin. 2013. A review on typhoon wind field modeling for disaster risk assessment. Progress in Geography 32(6): 852-867 (in Chinese).

FEMA (Federal Emergency Management Agency). 2012. HazusMH 2.1 Hurricane model technical manual. Washington, DC: Mitigation Division, Department of Homeland Security Federal Emergency Management Agency.

FIU (Florida International University). 2011. Florida public hurricane loss model 4.1. Miami, FL: Florida International University.

Georgiou, P.N., A.G. Davenport, and B.J. Vickery. 1983. Design wind speeds in regions dominated by tropical cyclones. Journal of Wind Engineering and Industrial Aerodynamics 13(1-3): 139-152.

Giuliani, G., and P. Peduzzi. 2011. The PREVIEW Global Risk Data Platform: A geoportal to serve and share global data on risk to natural hazards. Natural Hazards and Earth System Science 11(1): 53-66.

Goldstein, J., J.-D. Langlois, M. Dimitrijevic, M. Sadoud, and V. David. 2008. Approaches for extreme wind speed assessment: A case study. In Proceedings of the 7th World Wind Energy Conference, 24-26 June 2008, Helimax Energy Inc., Kingston, Canada, $1-8$

Guha-Sapir, D., R. Below, and P. Hoyois. 2013. EM-DAT: International disaster database. Brussels, Belgium: Université Catholique de Louvain. http://www.emdat.be. Accessed 1 Sept 2017.

Harper, B.A. 2001. Queensland climate change and community vulnerability to tropical cyclones: Ocean hazards assessment -
Stage 1. Queensland: Systems Engineering Australia Pty Ltd, Bureau of Meteorology, and James Cook University.

Harper, B.A. 2002. Tropical cyclone parameter estimation in the Australian region: Wind-pressure relationships and related issues for engineering planning and design-A discussion paper. SEA Report No. J0106-PR003E. Report prepared by Systems Engineering Australia Pty. Report prepared for Woodside Energy.

Harper, B.A., and G.J. Holland. 1999. An updated parametric model of the tropical cyclone. In Proceedings of the 23rd Conference on Hurricanes and Tropical Meteorology, 10-15 January 1999, American Meteorological Society, Dallas, Texas, USA.

Holland, G. 2008. A revised hurricane pressure-wind model. Monthly Weather Review 136(9): 3432-3445.

Huang, Z., D.V. Rosowsky, and P.R. Sparks. 2001. Long-term hurricane risk assessment and expected damage to residential structures. Reliability Engineering and System Safety 74(3): 239-249.

Islam, T., and R.E. Peterson. 2008. Tropical cyclone wind characteristics for the Bangladesh coast using Monte Carlo simulation. Journal of Applied Sciences 8(7): 1249-1255.

Jakobsen, F., and H. Madsen. 2004. Comparison and further development of parametric tropical cyclone models for storm surge modelling. Journal of Wind Engineering and Industrial Aerodynamics 92(5): 375-391.

Jarvis, A., H.I. Reuter, A. Nelson, and E. Guevara. 2008. Hole-filled SRTM for the globe version 4. Available from the CGIAR-CSI SRTM 90 m Database. http://srtm.csi.cgiar.org. Accessed 23 Jul 2017.

Knapp, K.R., M.C. Kruk, D.H. Levinson, H.J. Diamond, and C.J. Neumann. 2010. The international best track archive for climate stewardship (IBTrACS): Unifying tropical cyclone data. Bulletin of the American Meteorological Society 91(3): 363-376.

Landsea, C.W., C. Anderson, N. Charles, G. Clark, J. Dunion, J. Fernandez-Partagas, P. Hungerford, C. Neumann, and M. Zimmer. 2004. The Atlantic hurricane database re-analysis project: Documentation for the 1851-1910 alterations and additions to the HURDAT database. In Hurricanes and typhoons: Past, present and future, ed. R.J. Murnane, and K.B. Liu, 177-221. New York: Columbia University Press.

Landsea, C.W., and J.L. Franklin. 2013. Atlantic hurricane database uncertainty and presentation of a new database format. Monthly Weather Review 141(10): 3576-3592.

Lee, Y.-K., S. Lee, and H.-S. Kim. 2009. Evaluation of wind hazard over Jeju Island. In Proceedings of the 7th Asia-Pacific Conference on Wind Engineering, 8-12 November 2009, Taipei, China. http://www.iawe.org/Proceedings/7APCWE/M2B_6.pdf. Accessed 25 Jul 2017.

Levinson, D.H., H.J. Diamond, K.R. Knapp, M.C. Kruk, and E.J. Gibney. 2010. Toward a homogenous global tropical cyclone best-track dataset. Bulletin of the American Meteorological Society 91(3): 377-380.

Li, X.Y., W.H. Fang, and W. Lin. 2014. Comparison of interpolation methods for tropical cyclone track and intensity over Northwestern Pacific basin. Journal of Beijing Normal University (Natural Science) 50(2): 111-116 (in Chinese).

Lin, W., and W.H. Fang. 2013. Regional characteristics of Holland B parameter in typhoon wind field model for Northwest Pacific. Tropical Geography 33(2): 124-132 (in Chinese).

Loveland, T.R., B.C. Reed, J.F. Brown, D.O. Ohlen, Z. Zhu, L. Yang, and J.W. Merchant. 2000. Development of a global land cover characteristics database and IGBP DISCover from $1 \mathrm{~km}$ AVHRR data. International Journal of Remote Sensing 21(6-7): 1303-1330.

Maharani, Y.N., S. Lee, and Y.-K. Lee. 2009. Topographical effects on wind speed over various terrains: A case study for Korean 
Peninsula. In Proceedings of the 7th Asia-Pacific Conference on Wind Engineering, 8-12 November 2009, Taipei, China. http:// www.iawe.org/Proceedings/7APCWE/T2D_5.pdf. Accessed 25 Jul 2017.

McConochie, J.D., T.A. Hardy, and L.B. Mason. 2004. Modelling tropical cyclone over-water wind and pressure fields. Ocean Engineering 31(14): 1757-1782.

Mctaggart-Cowan, R., L.F. Bosart, C.A. Davis, E.H. Atallah, J.R. Gyakum, and K.A. Emanuel. 2006. Analysis of Hurricane Catarina (2004). Monthly Weather Review 134(11): 3029-3053.

Meng, Y., M. Matsui, and K. Hibi. 1997. A numerical study of the wind field in a typhoon boundary layer. Journal of Wind Engineering and Industrial Aerodynamics 67-68: 437-448.

Ngo, T.T., and C.W. Letchford. 2009. Experimental study of topographic effects on gust wind speed. Journal of Wind Engineering and Industrial Aerodynamics 97(9-10): 426-438.

Nolan, D.S., J.A. Zhang, and D.P. Stern. 2009. Evaluation of planetary boundary layer parameterizations in tropical cyclones by comparison of in situ observations and high-resolution simulations of Hurricane Isabel (2003). Part I: Initialization, maximum winds, and the outer-core boundary layer. Monthly Weather Review 137(11): 3651-3674.

Prigent, C., I. Tegen, F. Aires, B. Marticoréna, and M. Zribi. 2005. Estimation of the aerodynamic roughness length in arid and semiarid regions over the globe with the ERS scatterometer. Journal of Geophysical Research: Atmospheres 110(D9): 1-12.

Ramli, N.I., M.I. Ali, M.S.H. Saad, and T.A. Majid. 2009. Estimation of the roughness length (zo) in Malaysia using satellite image. In Proceedings of 7th Asia-Pacific Conference on Wind Engineering, 8-12 November 2009, Taipei, China. http://www.iawe.org/ Proceedings/7APCWE/T2D_1.pdf. Accessed 23 Jul 2017.

Rupp, J.A., and M.A. Lander. 1996. A technique for estimating recurrence intervals of tropical cyclone-related high winds in the tropics: Results for Guam. Journal of Applied Meteorology 35(5): 627-637.

Russell, L.R. 1969. Probability distributions for Texas Gulf coast hurricane effects of engineering interest. Ph.D. dissertation. Department of Civil Engineering, Stanford University, Stanford, California.

SAC (Standardization Administration of China). 2006. Grade of tropical cyclone GB/T 19201-2006. Beijing: SAC (in Chinese).

Shi, P., and R. Kasperson. 2015. World atlas of natural disaster risk. London and Beijing: Springer and Beijing Normal University.

Silva, J., C. Ribeiro, and R. Guedes. 2007. Roughness length classification of Corine Land Cover classes. In Proceedings of the European Wind Energy Conference, 7-10 May 2007, Milan, Italy, $1-10$.

Skamarock, W.C., J.B. Klemp, J. Dudhia, D.O. Gill, D.M. Barker, W. Wang, and J.G. Powers. 2005. A description of the advanced research WRF version 2. Boulder, CO: Mesoscale and Microscale Meteorology Division, National Center for Atmospheric Research.

Standards Australlia / Standards New Zealand. 2002. Structural design actions. Part 2: Wind actions AS/NZS 1170.2: 2002. Sydney and Wellington: Standards Australlia International and Standards New Zealand.

Summons, N., and C. Arthur. 2011. Tropical cyclone risk model user guide. Canberra, Australia: Commonwealth of Australia (Geoscience Australia). https://storage.googleapis.com/google-codearchive-downloads/v2/code.google.com/tcrm/tcrm_user_guide. pdf. Accessed 28 Jul 2017.
Takahashi, K. 1939. Distribution of pressure and wind in a typhoon. Journal of the Meteorological Society of Japan 17(2): 417-421.

Tiago de Oliveira, J. 1963. Decision results for the parameters of the extreme value (Gumbel) distribution based on the mean and the standard deviation. Trabajos de Estadistica $Y$ de Investigacion Operativa 14(1): 61-81.

UNISDR (United Nations International Strategy for Disaster Reduction). 2009. Global assessment report on disaster risk reduction. Geneva: United Nations.

UNISDR (United Nations International Strategy for Disaster Reduction). 2011. Global assessment report on disaster risk reduction. Geneva: United Nations.

UNISDR (United Nations International Strategy for Disaster Reduction). 2013. Global assessment report on disaster risk reduction. Geneva: United Nations.

UNISDR (United Nations International Strategy for Disaster Reduction). 2015. Global Assessment Report on disaster Risk Reduction. Geneva: United Nations.

USGS (U.S. Geological Survey). 1996. GTOPO30: Global 30 arcseconds digital elevation model. Data available from the U.S. Geological Survey. https://lta.cr.usgs.gov/GTOPO30. Accessed 21 Jul 2017.

USGS (U.S. Geological Survey). 2001. Global land cover characteristics database version 2.0. Data available from the U.S. Geological Survey. https://lta.cr.usgs.gov/GLCC. Accessed 21 Jul 2017.

Vickery, P.J., P.F. Skerlj, and L.A. Twisdale. 2000. Simulation of hurricane risk in the US using empirical track model. Journal of Structural Engineering 126(10): 1222-1237.

Vickery, P.J., and D. Wadhera. 2008. Statistical models of Holland pressure profile parameter and radius to maximum winds of hurricanes from flight-level pressure and $\mathrm{H}^{*}$ Wind data. Journal of Applied Meteorology and Climatology 47(10): 2497-2517.

Wieringa, J. 1992. Updating the Davenport roughness classification. Journal of Wind Engineering and Industrial Aerodynamics 41(1): 357-368.

Wieringa, J., A.G. Davenport, C.S.B. Grimmond, and T.R. Oke. 2001. New revision of Davenport roughness classification. In Proceedings of the 3rd European and African Conference on Wind Engineering, 2-6 July 2001, Eindhoven, The Netherlands, 1-8.

Willoughby, H.E., R.W.R. Darling, and M.E. Rahn. 2006. Parametric representation of the primary hurricane vortex. Part II: A new family of sectionally continuous profiles. Monthly Weather Review 134(4): 1102-1120.

Wong, M.L.M., and J.C.L. Chan. 2007. Modeling the effects of landsea roughness contrast on tropical cyclone winds. Journal of the Atmospheric Sciences 64(9): 3249-3264.

Yan, B.W., Q.S. Li, Y.C. He, and P.W. Chan. 2013. Numerical simulation of topographic effects on wind flow fields over complex terrain. In Proceedings of the 8th Asia-Pacific Conference on Wind Engineering, 10-14 December 2013, Chennai, India, 541-550. Singapore: Research Publishing. http://iawe.org/ Proceedings/8APCWE/B.W.\%20Yan.pdf. Accessed 12 Mar 2017.

Ying, M., W. Zhang, H. Yu, X. Lu, J. Feng, Y. Fan, Y. Zhu, and D. Chen. 2014. An overview of the China Meteorological Administration tropical cyclone database. Journal of Atmospheric and Oceanic Technology 31(2): 287-301. 